\title{
A PRÁXIS PEDAGÓGICA DOS PROFESSORES DO CURSO DE EDUCAÇÃO FÍSICA DA UNIVERSIDADE PARANAENSE - UNIPAR UNIDADE DE UMUARAMA/PR
}

Danilo César Pereira ${ }^{1}$

PEREIRA, D. C. A práxis pedagógica dos professores do curso de educação física da Universidade Paranaense - UNIPAR Unidade de Umuarama/PR. EDUCERE - Revista da Educação, Umuarama, v, n. 1, p. 145168, jan./jun. 2017.

RESUMO: Atualmente a reflexão sobre as práxis e as qualificações pedagógicas do professor na docência do ensino superior tem mostrado a necessidade de estabelecer a relação da identidade do professor dentro do âmbito do ensino e analisar sua relevância no processo de formação dos futuros profissionais. Nesse sentido a universidade precisa ser entendida como um lugar de aquisição de conhecimento e de formação profissional, onde a práxis pedagógica é um fator determinante para a emancipação dos indivíduos nos processos formativos da aprendizagem. Esta pesquisa objetivou investigar a atuação do corpo docente do curso de Educação Física da Universidade Paranaense/UNIPAR unidade de Umuarama/Pr., e de que forma a práxis pedagógica e a formação continuada interferem na formação dos futuros profissionais. Este estudo se embasou na análise e interpretação de diversos dados obtidos em uma pesquisa de campo, onde se pretendeu buscar informações diretamente com a população pesquisada, por meio de um questionário, exigindo que o pesquisador reunisse diversas informações a serem documentadas a fim de compreender e explicar o problema pesquisado, e fundamentou-se em revisão de literatura através de livros e artigos científicos acerca da temática. Pode-se concluir que os professores universitários têm consciência em relação a sua formação, priorizam as aprendizagens significativas, embasadas em práticas liberais e éticas e buscam como ferramentas de trabalho diversos métodos

DOI: https://doi.org/10.25110/educere.v17i1.2017.6289

${ }^{1}$ Especialista em Docência e Gestão do Ensino Superior pela Universidade Paranaense - UNIPAR. Especialista em Educação Física Escolar e Recreação pela Faculdade Venda Nova do Imigrante FAVENI. Graduado em Educação Física - Licenciatura e Bacharelado, pela Universidade Paranaense - UNIPAR. Trabalha atualmente na Secretaria de Educação e Cultura do município de Pérola/Paraná, como professor de Educação Física na educação infantil. E-mail: dandan_just@hotmail.com 
a fim de enriquecer e aprimorar o conhecimento dos alunos, objetivando formar profissionais capacitados a enfrentar o mercado de trabalho e as situações adversas que podem surgir na sua atuação profissional.

PALAVRAS-CHAVE: Docência Superior; Prática pedagógica; Professor.

\section{THE PEDAGOGICAL PRAXIS OF THE TEACHERS IN THE COURSE OF PHYSICAL EDUCATION AT UNIVERSIDADE PARANAENSE - UNIPAR UNIDADE DE UMUARAMA/PR}

ABSTRACT: The reflection on the qualifications and the pedagogical praxis teacher's teaching in higher education, has shown the need to establish the relationship of teacher identity within the context of teaching and analyze its relevance in the process of formation of future professionals. In this sense the university needs to be understood as a place of knowledge acquisition and professional training, where the pedagogical praxis is a determining factor for the emancipation of the individuals in the formative processes of learning. This research aimed to investigate the role of the professors of Physical Education Course of Universidade Paranaense/UNIPAR unidade de Umuarama/PR and how the pedagogical praxis and continuing education interfere in the formation of future professionals. This study is based on the analysis and interpretation of several data obtained in a field research, where it is intended to seek information directly as a researched population, through a questionnaire, requiring the researcher to gather explain the problem researched, and was based on literature review by books and scientific articles on the subject. It can be concluded that the university professors are aware about their training, prioritize the significant learning, based on liberal and ethical practices and seek as work tools several methods in order to enrich and enhance the knowledge of students, aiming to train professionals able to face the labor market and the adverse situations that may arise on their professional activity.

KEYWORDS: Higher Education Teaching; Pedagogical Practice; Teacher. 


\section{LA PRAXIS PEDAGÓGICA DE LOS PROFESORES DEL CURSO DE EDUCACCIÓN FÍSICA DE LA UNIVERSIDAD PARANAENSE - UNIPAR UNIDAD DE UMUARAMA/PR}

RESUMEN: Actualmente, la reflexión sobre la praxis y las calificaciones pedagógicas del profesor en la docencia de enseñanza superior ha mostrado la necesidad de establecer la relación de identidad del profesor en el ámbito de la enseñanza y analizado su importancia en el proceso de formación de los futuros profesionales. En este sentido, la universidad necesita ser comprendida como un lugar de adquisición de conocimiento y de formación profesional, donde la praxis pedagógica es un factor determinante para la emancipación de los individuos en los procesos formativos de aprendizaje. Esta pesquisa tuvo como objetivo investigar la actuación del equipo docente del curso de Educación Física de la Universidad Paranaense/UNIPAR unidad Umuarama/Pr, y de que forma la práctica pedagógica y la formación continuada interfieren en la formación de los futuros profesionales. Este estudio se embazó en el análisis e interpretación de diversos datos obtenidos en una pesquisa de campo, donde se ha buscado informaciones directamente con la población encuestada, a través de un cuestionario, exigiendo que el investigador reuniera diversas informaciones a ser documentadas, con el fin de comprender y explicar el problema investigado, y se basó en revisión de literatura a través de libros y artículos científicos acerca del tema. Se puede concluir que los profesores universitarios tienen consciencia con relación a su formación, priorizan los aprendizajes significativos, embazados en prácticas liberales y éticas, y buscan como herramientas de trabajo diversos métodos para enriquecer y mejorar el conocimiento de los alumnos, buscando formar profesionales aptos a enfrentar el mercado de trabajo y las situaciones contrarias que pueden surgir en su actuación profesional.

PALABRAS CLAVE: Docencia superior; Práctica pedagógica; Profesor.

\section{INTRODUÇÃO}

A importância da formação docente tem sido, nos últimos anos, estabelecida pelo Ministério da Educação como uma das prioridades, em termos de estratégia, para a melhoria do ensino no Brasil (LIMA e COR- 
RÊA, 2010).

Segundo Ghilardi (1999), nos últimos anos houve uma mudança na situação educacional da sociedade, e atualmente a formação inicial do professor e o trabalho docente é algo extremamente dinâmico e que esta em constante transformação, assim como a própria comunidade acadêmica e a sociedade. O cenário em que este personagem do ensino superior esta inserido, encontra-se bem diferente do cenário de alguns anos atrás, visto que é de suma importância este se manter em constante atualização, seja por cursos, palestras, workshops, conferências, etc., oferecidos pela própria instituição em que trabalha ou até mesmo pela sua busca de conhecimento fora dela.

Este processo de formação e atualização trata-se especialmente sobre a construção de saberes docentes, visto que essa construção vai além do mero conhecimento acadêmico e desta forma, é pertinente a citação de Pimenta (2000) ao afirmar que por meio de troca de experiências e vivências, além de adquirirem um aprendizado mútuo, facilitam a determinação dos saberes emergentes no âmbito acadêmico, bem como a consolidação de situações de socialização e união de sua classe trabalhista. Desta forma, os docentes devem sempre manter-se atentos às mudanças, tanto da sociedade quanto no âmbito educacional, observando e analisando o que seus alunos trazem como bagagem escolar, tendo coerência para aplicar métodos de ensino aprendizagem, condizentes com os profissionais que desejam formar.

Frente a isto, o que se espera de um corpo docente de uma Universidade, como destaca André (2001), é que assumam com competência e responsabilidade a tarefa de ensinar com qualidade, para que seus alunos apropriem-se de conhecimentos significativos para sua inserção ativa na sociedade, por meio de uma práxis pedagógica reflexiva, criadora e crítica aplicada por ele. Ainda, dentro do trabalho docente, é exigido que o professor possua algumas qualificações e/ou titulações (lato sensu, stricto sensu), e especificamente no ensino superior, é observável que há uma grande valorização das mesmas, pois através delas o professor esta cada vez mais presente nas atualizações acerca de sua especialidade, e julga-se de extrema importância que o corpo docente dos cursos de ensino superior possuam docentes especialistas, mestres, doutores e com pós doutorado. 
O tema abordado neste trabalho proporcionou a investigação da atuação do professor do curso de Educação Física da Universidade Paranaense/UNIPAR unidade de Umuarama/Pr., e de que forma esta interfere na formação de futuros profissionais da área, tendo o intuito de investigar como é a atuação do referido corpo docente e como a práxis pedagógica e a formação continuada interferem na formação dos futuros profissionais de Educação Física.

\section{DOCÊNCIA UNIVERSITÁRIA E PRÁTICA PEDAGÓGICA NO PROCESSO DE FORMAÇÃO EM NÍVEL SUPERIOR: UM DIS- CURSO ATUAL}

Em seu livro, Lima (2010, p. 08) diz que:

A educação escolar dá-se num local específico, instituído com a finalidade de organizar, formalizar e universalizar o conhecimento historicamente produzido. Esta instituição, como o nome pontua, é a escola. A escola em suas distintas modalidades e níveis - Ensino Fundamental, Ensino Médio, EJA, Ensino Técnico-profissionalizante ou Ensino Superior - é constituída por vários atores sociais.

Sendo a Universidade um nível de ensino escolar, podemos ver que com o passar dos tempos, ela assumiu um papel de suma importância no processo de formação do cidadão e conquistou um espaço relevante no âmbito educacional e social. Em decorrência dessa importância, se faz necessário analisar as práxis pedagógicas do docente, no intuito de melhorar sua ação pedagógica. Vale ressaltar, que para uma instituição de ensino receber o título de Universidade, ela precisa dedicar-se à produção e transmissão de conhecimento, através das atividades de ensino, pesquisa e extensão.

Partindo desse pensamento e analisando Lima (2010), podemos dizer que um dos principais atores na organização de processos e métodos de ensino e aprendizagem é o professor e de acordo com Gómez (2001), temos que concebê-lo, como um profissional que reflete criticamente sobre a prática cotidiana, a fim de compreender as características específicas daqueles processos, bem como sobre o contexto em que o 
ensino tem lugar para que possa, assim, facilitar o desenvolvimento autônomo e emancipador dos participantes do processo educativo. No dizer de Pimenta (2008, p.20), "ser professor também se faz com a experiência socialmente acumulada, as mudanças históricas da profissão", e ainda refletindo sobre o trabalho desse docente na vida do aluno, o mesmo consegue ver o mundo de maneira distinta, pois o seu processo de formação inicial e continuado é protagonista para um satisfatório desempenho de sua prática pedagógica.

Dessa forma, pode-se traçar um paralelo entre a instituição de ensino superior e o docente, acreditando ser possível, fazer com que os docentes, criem e recriem situações, nos quais possam de fato, refletir sobre as suas próprias práticas e métodos de ensino-aprendizagem, sempre tendo em mente que deve ser levada em consideração a tríade: professor, aluno e aprendizagem.

O estudo se caracterizou como uma pesquisa de campo, que de acordo com Marconi e Lakatos (2003, p. 186) "esta é utilizada com o objetivo de conseguir informações e/ou conhecimentos acerca de um problema, para qual se procura uma resposta, ou de uma hipótese, que se queira comprovar, ou, ainda, descobrir novos fenômenos ou as relações entre eles". Tratando-se assim de uma pesquisa do tipo qualitativa que, segundo Lüdke e André (1986, p.18), “[...] se desenvolve numa situação natural, é rico em dados descritivos, tem um plano aberto e flexível e focaliza a realidade de forma complexa e contextualizada [...]". Para o embasamento teórico, realizou-se uma pesquisa bibliográfica, que de acordo com Gil (2002, p. 44) "é desenvolvida com base em material já elaborado, constituído principalmente de livros e artigos científicos". Esta tem por objetivo colocar o pesquisador em contato direto com o que já foi produzido sobre o tema da sua pesquisa, que possibilita a fundamentação teórica, sendo imprescindível para a realização de estudos históricos.

Como critério de seleção da amostragem, a pesquisa foi realizada com os docentes do Curso de Educação Física da Universidade Paranaense/UNIPAR unidade de Umuarama/Pr, que concordaram em assinar o Termo de Consentimento de Livre Esclarecido (TCLE), e como critério de exclusão da pesquisa, foi adotado, o docente que se negou a responder o questionário e/ou não assinou o Termo de Consentimento de Livre Esclarecido (TCLE). Foram convidados a participarem do estudo os 25 
professores que fazem parte do corpo docente do referido curso, porém colaboraram com o estudo 19 docentes de ambos os sexos, em que se constata que seis docentes se negaram a participar.

Cabe situar ao leitor que como instrumento de coleta de dados foi utilizado um questionário estruturado com sete perguntas fechadas do tipo múltipla escolha e sete perguntas abertas, com questões que versão sobre o objetivo do estudo. O questionário foi aplicado em forma de entrevista em que se interrogam diretamente pessoas por meio de uma série de perguntas ordenadas, que são respondidas por escrito sem a intervenção direta do entrevistador (GIL, 2008). O instrumento de coleta dos dados foi validado por meio de parecer do comitê de ética (CEPEH), $\mathrm{n}^{\mathrm{o}} 120574 / 2015$, que verificou a validade e fidedignidade do mesmo. Ao final da coleta, os dados foram descritos e analisados sistematicamente de acordo com a temática da pesquisa em questão.

Face ao exposto, o trabalho ora proposto teve por objetivo investigar a práxis pedagógica e a formação continuada dos professores que atuam no curso de Educação Física da Universidade Paranaense/UNIPAR unidade de Umuarama/Pr., verificando as formas de atualização/aperfeiçoamento e se as mesmas são condizentes com a sua atuação (disciplinas e/ou projetos) dentro da Universidade, analisando sua didática e seus métodos de ensino/aprendizagem, identificando assim quais os benefícios que o docente vê sobre a sua prática e seu papel relevante na formação de futuros profissionais da área.

\section{RESULTADOS E DISCUSSÃO}

O foco deste estudo foi o professor do ensino superior, que exerce o importante papel de formador no processo de ensino aprendizagem na sua atuação profissional, sendo assim, os questionários foram respondidos pelo corpo docente do curso de Educação Física da UNIPAR, campus Umuarama/Pr, e os resultados foram relatados qualitativamente de forma que o leitor possa alcançar, em sua leitura, uma reflexão da realidade pesquisada. 


\section{PROFESSOR NO ENSINO SUPERIOR: CARACTERIZAÇÃO, FORMAÇÃO E INSERÇÃO NESTE ÂMBITO}

Conforme análise da pesquisa, o referido curso apresenta oito docentes do sexo masculino e 11 docentes do sexo feminino. A faixa etária dos docentes é bem variada, pois temos nove docentes com idade entre 27 e 34 anos, cinco tem idade entre 36 e 46 anos, dois com idade acima de 50 anos e três docentes não informaram a idade.

$\mathrm{Na}$ caracterização da graduação dos docentes entrevistados, evidencia-se que dos 19 professores, 12 são graduados em Educação Física e os demais são oriundos das mais diversas graduações, sendo elas: Letras (português/inglês), Filosofia, Farmácia, História, Pedagogia, Ciências Biológicas e Nutrição. Para tanto, faz-se necessário que professores com outra graduação façam parte do referido curso, pois, o mesmo possui disciplinas específicas das quais não é competência dos graduados em Educação Física e de acordo com Arantes (1997), essa competência envolve a capacidade que o professor tem para articular seu conhecimento teórico à sua prática profissional, considerando as experiências pessoais que o mesmo "carrega" desde a tenra idade, as vivências acadêmicas pelas quais passou e as situações que o sensibilizaram.

Sabendo que para ingressar no exercício da docência no ensino superior, o professor deve possuir especialização como formação acadêmica e analisando o perfil dos entrevistados, verificou-se que a maioria dos docentes, sendo eles 13, possui mestrado nas mais diversas áreas: Biotecnologia, Ciência Farmacêutica, Educação, Educação Física, Filosofia e Ética, Imunologia, Pedagogia da Motricidade, Pedagogia do Movimento, Promoção da Saúde, Teoria e prática da Educação Física, e sete possuem especialização, na área da Educação Física, sendo elas em: Dança, Educação Física Escolar, Exercício Físico/Reabilitação Cardíaca, Ginástica Rítmica, Nutrição Funcional, Treinamento Desportivo e Personalizado (aparece soma maior que 19, pois um docente possui duas especializações), e ainda encontramos dois docentes que estão cursando o doutorado.

$\mathrm{Na}$ análise da LDB (BRASIL, 1996), fica claro que o docente universitário deve ter competência técnica compreendida como domínio da área de conhecimento. Tal competência aparece no artigo 52, inciso 
II onde é determinado que as universidades são instituições pluridisciplinares de formação dos quadros profissionais de nível superior que se caracterizam por possuir $1 / 3$ do corpo docente, pelo menos com titulação acadêmica de mestrado ou doutorado. Para se adequar a essa realidade, o professor deve tornar-se um sujeito em permanente construção e desta forma, é necessário que ele alastre seu conhecimento acerca de sua função acadêmica e das possibilidades da sua formação continua e profissional, pois, assim terá inúmeras possibilidades de despertar sua consciência para uma identificação docente que amplie seu entendimento de ensino, permitindo uma nova visão dos princípios que regem o seu trabalho de docente e em conseqüência, um novo docente.

O curso de Educação Física existe na Unipar Unidade de Umuarama desde 1998, e em quase duas décadas, inúmeros docentes passaram pelo referido curso. De acordo com análise dos resultados obtidos na pesquisa, sobre a inserção dos docentes na referida instituição, verifica-se que 13 docentes ingressaram na universidade por processo seletivo e os outros seis, por diferentes motivos, sendo que um foi convidado a trabalhar na universidade, um já era funcionário da instituição e por ter formação em Educação Física o seu regime de trabalho foi alterado, passando este a ocupar cargo de docente, um teve seu ingresso por análise de currículo e os outros três não informaram.

Ao responderem sobre seu tempo de trabalho, encontramos os seguintes resultados: oito docentes exercem função na instituição a mais de dez anos, três professores trabalham entre cinco e dez anos, seis fazem parte do quadro de funcionários entre um e cinco anos, e outros dois docentes estão a um ano na universidade.

Em relação à jornada de trabalho, temos nove professores horistas, dois T20, dois T30 e seis T40, sendo que apenas quatro docentes têm dedicação exclusiva para a instituição e os outros 15 trabalham em algum outro lugar. A lei no 4.881-A, de 06 de dezembro de 1965, que instituiu o regime de trabalho do docente de nível superior, em seu artigo 39 conceituou o "regime de tempo integral", como sendo:

[...] o exercício da atividade funcional com dedicação exclusiva, em que o ocupante de cargo do magistério superior fica proibido de exercer, cumulativamente, qualquer outro cargo embora de magistério, ou qualquer função ou atividade que 
tenha caráter de emprego (BRASIL, 1965).

Seguindo, ainda, a LDB (BRASIL, 1996), em seu artigo 52, inciso III, ela determina que as universidades são instituições que se caracterizam por, possuir em seu quadro de funcionários, 1/3 do corpo docente em regime de tempo integral. Este regime de trabalho dos docentes é de grande importância para o curso de graduação, pois são os mesmos que desenvolvem as atividades de ensino, pesquisa e extensão, dentro do curso em que são enquadrados, traçando um paralelo com as disciplinas que ministram dentro do curso e desta forma consegue por em vigor o que diz no inciso III do artigo 53 da LDB (BRASIL, 1996), que dentre as atribuições dos docentes, esta a de "estabelecer planos, programas e projetos de pesquisa científica, produção artística e atividades de extensão".

Tendo em mente os pilares que constitui uma universidade ensino, pesquisa e extensão - e como já mencionado, que os docentes enquadrados desenvolvem suas atividades embasadas nesses pilares, a indagação ficou acerca da pesquisa, pois ela auxilia na construção de situações de ensino numa perspectiva mais emancipatória e menos praticista e a prática investigativa do professor ajudará o aluno a compreender, por meio da reflexão, os fenômenos complexos que acontecem no espaço da sala de aula (SANTOS, 2010). Os docentes ao serem interpelados sobre apresentação de trabalhos em evento científico do curso e da própria instituição dão as seguintes respostas: no ano de 2013, dez professores, orientando alunos, apresentaram 31 trabalhos; no ano de 2014, 13 docentes, como orientadores de alunos, apresentaram 46 trabalhos e no ano de 2015, 14 docentes, orientaram e apresentaram 48 trabalhos científicos. Nota-se, com o passar dos anos, que a quantidade de trabalhos apresentados aumentou e os docentes que não apresentam trabalhos nos eventos científicos, diminuiu. Considerando a fala de Santos (2010) e o trabalho de pesquisa desenvolvido na universidade, por meio dos projetos de iniciação científica (PIC e PIBIC), o docente deve consolidar essa postura, pois a aquisição do conhecimento por meio do processo de investigação faz da pesquisa um alicerce do conhecimento no processo de formação do indivíduo nos cursos superiores e segundo André (1997), a pesquisa pode tornar o professor capaz de refletir sobre sua prática profissional e de buscar formas (conhecimentos, habilidades, atitudes, relações) que o 
ajudem a aperfeiçoar cada vez mais seu trabalho docente.

São inúmeras as possibilidades que o docente tem para desenvolver seu trabalho dentro de uma universidade, e com isso o nível de satisfação com a profissão da docência pode revelar-se como uma temática importante dentro desse trabalho e de acordo com Santos (2010), compreende-se que a satisfação que se tem com o desempenho da atividade poderá contribuir positivamente para o crescimento individual e profissional do sujeito. Ao analisar o grau de satisfação que o docente tem com a sua profissão, encontramos o seguinte resultado: dez professores julgam excelente a sua satisfação, nove julgam como ótimo e nenhum marcou as opções bom, ruim e péssimo. Quando interrogados com essa questão, a intenção foi despertar o docente sobre como se sentem em relação a sua profissão, sobre esse sentimento, que é quase explícito no trabalho do professor e permitiu-nos, também, um encontro com profissionais que sentem prazer no que fazem, e faz-nos pensar ainda, mesmo que haja discussão sobre impasses da profissão, estes docentes se sentem realizados/ satisfeitos e têm um olhar diferenciado para sua profissão (como verificado nas respostas). Outra questão, que podemos refletir até agora sobre os docentes entrevistados, é que eles apresentam ideias muito parecidas, mesmo tendo formações e tempo de serviço diferente no ensino superior, sendo comum a sua concepção de ensino e sentimentos de satisfação em desenvolver o trabalho no ensino superior.

\section{A RELAÇÃO PROFESSOR, METODOLOGIA, FORMAÇÃO CONTINUADA E CURRÍCULO DE CURSO DA DOCÊNCIA NO ENSINO SUPERIOR}

No enredo sobre a discussão acerca da formação do professor universitário e as circunstâncias pelas quais esses adentram no ensino superior, aparecem reflexões sob os diferentes enfoques alusivos as práticas pedagógicas e metodológicas que movem a docência. Pimenta e Anastasiou (2002), referindo-se ao processo da docência no ensino superior, dizem que:

O avançar no processo de docência e do desenvolvimento profissional, mediante a preparação pedagógica não se dará em separado de processos de desenvolvimento pessoal e institu- 
cional: este é o desafio a ser hoje, considerado na construção da docência no ensino superior (p.259).

Partindo desse pressuposto, entende-se que a construção da formação do professor se dá a partir da graduação (base importante para a docência) e se delonga até a formação continuada. Percebemos, nesta pesquisa, que os docentes do curso de Educação Física da Unipar, Unidade de Umuarama/Pr, não estagnaram na graduação e procuraram uma especialização, sendo ela lato sensu e/ou stricto sensu, pois adotaram uma atitude de buscar novos conhecimentos e aprimorar os já adquiridos, e vale destacar que existem diversas maneiras de realizar uma formação continuada. Ao se depararem com a temática sobre atualização/aperfeiçoamento dentro da sua área da atuação os professores entrevistados nos apresentam os seguintes dados: oito professores participam de cursos/ workshops, 14 docentes participam de palestras e debates, 15 professores participam de simpósios, seminários e conferências, 11 professores participam de eventos científicos, três professores ingressaram uma nova especialização (um lato sensu e dois stricto sensu), um participa de organização de eventos desportivos. Quando perguntado, onde são feitas essas atualizações, 16 professores dizem que é dentro da própria instituição, 13 professores relatam que é necessário complementar isto fora da instituição e um professor diz que é necessário buscar essa atualização/aperfeiçoamento fora da instituição, pois a UNIPAR não oferece (aparece soma maior que 19, pois os docentes podiam marcar mais que uma alternativa).

Em relação à formação continuada, Nóvoa (1992) afirma que:

A formação não se constrói por acumulação de cursos, conhecimentos ou técnicas, mas sim através de um trabalho de reflexividade crítica sobre as práticas e de (re)construção permanente de uma identidade pessoal. Por isso é tão importante investir na pessoa e dar um estatuto de saber a experiência ( $\mathrm{p}$. 25).

Neste contexto, em que a formação não depende exclusivamente de cursos, workshops, simpósios, palestras, debates, etc..., faz-se necessário considerar outras causas que influenciam a formação do professor, pois no dizer de Pimenta (2001), ser professor se faz com experiência 
socialmente acumulada, as mudanças históricas da profissão, o exercício profissional em diferentes ambientes educacionais, a não valorização social e financeira dos docentes, as dificuldades de estar diante de turmas numerosas em escolas precárias e Imbernón (2000) diz que a formação continuada deve ir além, e estender-se ao terreno das capacidades, habilidades e atitudes, fazendo com que os valores e concepções de cada professor sejam permanentemente questionados, abandonando-se a ideia de que a formação restringe-se apenas à atualização científica, didática e psicopedagógica.

De acordo com Perrenoud (1999) a formação continuada tem, entre outros, o objetivo de propor discussões teóricas que possam colocar os profissionais atualizados em termos de novas metodologias de ensino e, com isto, contribuir para as mudanças que se fazem necessárias para a melhoria da ação pedagógica no ambiente educacional e, conseqüentemente, da educação.

Dentro do processo ensino-aprendizagem o docente assume uma didática ao escolher determinados métodos para alcançar/atingir seus objetivos em relação aos alunos, onde um desses objetivos é dar possibilidades a aquisição de conhecimento aos mesmos. Nesse sentido, para que o processo de ensino-aprendizagem seja desenvolvido com êxito, o professor, além do conhecimento do conteúdo específico, precisa também do conhecimento pedagógico que o habilite a trabalhar esse conteúdo de forma a promover a aprendizagem do discente, ou seja, o professor precisa criar estratégias para transformar a matéria em função de condicionantes como o tempo, o projeto pedagógico, a motivação dos alunos, dentre outros (TARDIF, 2002).

Ao se defrontarem com a questão sobre as metodologias utilizadas no exercício da prática docente, a fim de possibilitar um processo de ensino-aprendizagem mais crítico e significativo na vida acadêmica dos alunos. Todos os professores entrevistados relacionaram que usam aulas expositivas (momento em que o docente é detentor da palavra), 18 professores utilizam aulas práticas (momento dos alunos vivenciarem a teoria), 14 professores aderem apresentação de trabalhos dentro de sala de aula, 13 professores trabalham com debates (discussão entre alunos para colocarem suas ideias em questão, concordando e/ou discordando das demais), 13 professores recorrem ao estudo de caso (instrumento que 
contribui para compreender melhor alguns fenômenos individuais), sete professores aplicam fórum de discussão (discussão em ambiente virtual entre alunos para colocarem suas ideias em questão, concordando e/ ou discordando das demais), quatro professores utilizam a pesquisa exploratória (utilizada para familiarizar-se com o fenômeno que será investigado), quatro professores adotam em sua metodologia realização de seminário integrado (transmite conhecimentos específicos relacionados a determinado assunto) (aparece soma maior que 19, pois os docentes podiam marcar quantas alternativas quisesse).

Diante de tantas metodologias que podem ser utilizadas para os fins educacionais, Naves (2015) ressalta que a metodologia que o professor usará, deve constar no plano de ensino, pois ela é a forma como ele irá trabalhar, os recursos didáticos que auxiliarão a promover o aprendizado e a circulação do conhecimento. Pode-se dizer, também, que as metodologias e técnicas de ensino são em si, mas um dos fazeres interventivos possíveis no processo ensino-aprendizagem, em que todos ganham, pois, entendemos estes instrumentos como veículos educacionais, que podem e devem ser repensados de forma dinâmica, à medida que houver solicitação das necessidades do estudante, no próprio cotidiano escolar (LIMA, 2010). Assim, fica evidente que os docentes do referido curso utilizam as mais diversas maneiras de ensino, o que favorece um aprendizado de qualidade e dinamizam mais as aulas, aguçando ainda mais o interesse do discente.

Atrelada a esse pensamento, pode-se estabelecer a ideia de que, quanto mais conhecimento específico o professor possuir melhor será a atuação na formação do aluno, tornando-se, desta forma, indiscutível que o conhecimento é imprescindível para expandir, de maneira satisfatória, o processo de ensino-aprendizagem como um todo.

Ainda assim, nota-se que as metodologias são de suma importância no processo ensino-aprendizagem e traçando um paralelo, não se pode esquecer a grade curricular do curso, pois ela traz em si, matérias afins que podem ser trabalhadas em conjunto, unificando cada vez mais o curso e assim aumentando o elo de interdisciplinaridade.

De acordo com os Parâmetros Curriculares Nacionais:

A interdisciplinaridade não dilui as disciplinas, ao contrário, mantém sua individualidade. Mas integra as disciplinas a partir 
da compreensão das múltiplas causas ou fatores que intervêm sobre a realidade e trabalha todas as linguagens necessárias para a constituição de conhecimentos, comunicação e negociação de significados e registro sistemático dos resultados. (BRASIL, 1999, p. 89).

Partindo dessa premissa, foi questionado aos docentes se há interdisciplinaridade no currículo do curso de Educação Física, e apresentaram-se as seguintes respostas: 15 docentes afirmam que ela existe dentro do referido curso e apontaram as formas que aparecem: seis professores afirmam que os cursos e eventos do próprio curso trabalham esta questão, quatro professores dizem que ela se apresenta na própria matriz curricular, outros quatro professores relatam que realizam atividades desenvolvidas entre disciplinas afins, três professores dizem que a interdisciplinaridade é trabalhada através da PCC (prática como componente curricular) em que algumas disciplinas já tem carga horária para tal atividade, dois professores dizem que realizam reuniões pedagógicas de incentivo e estímulo a interdisciplinaridade. Um professor diz que a integração da interdisciplinaridade é possível através do bom relacionamento da equipe, um professor diz que acontece por meio de atividades de discussão, trabalhos e pesquisas e um professor relata que é trabalhada dentro da própria disciplina (aparece soma maior que 15, pois os docentes podiam responder o que quisesse). Contudo, quatro professores dizem que não há interdisciplinaridade dentro do curso e apontam que as dificuldades que impedem de ela ser realizada são: falta iniciativa do corpo docente, a carga horária é insuficiente, dificuldade no contato com os outros professores e falta conexão com as disciplinas do currículo do curso.

Podemos constatar certo confronto de ideias entre os docentes e até a própria bibliografia, pois nela consta, como já mencionado, a integração das disciplinas do currículo de um determinado curso, e fica evidente que não tem como formar profissionais sem, no momento da graduação, fazer uma relação com as disciplinas da grade curricular, pois trabalhar de maneira isolada não é a forma mais indicada para a construção de um profissional reflexivo e crítico, os horizontes têm que ser expandidos na formação inicial desse futuro profissional. 


\section{DOCÊNCIA UNIVERSITÁRIA E A PRÁXIS PEDAGÓGICA NO PROCESSO DE FORMAÇÃO DO INDIVIDUO}

Sendo o foco desta pesquisa o docente universitário, sua práxis pedagógica frente à formação superior e o importante papel que exerce no processo de ensino e aprendizagem, foi exposto até o presente momento que os professores buscam ao máximo manter-se atualizados dentro da sua área de formação e atuação profissional, analisadas as mais diversas metodologias adotadas pelos mesmos e discutida a interdisciplinaridade do curso.

Analisa-se, também, até o presente momento que somente o ensino (teoria), na concepção mais tradicional, não é suficiente para atender as mudanças que entram nos campos profissionais e pessoais. Atualmente, não há como pensar/refletir a teoria desvinculada da prática, pois esse conhecimento teórico é que respalda o docente no trabalho prático, e assim essa relação teoria e prática andam paralelamente em busca de um objetivo. Essa relação é chamada por Vázquez de Práxis e ele ainda diz que "[...] toda práxis é atividade, mas nem toda atividade é práxis" (VÁZQUEZ, 1997, p.185), ou seja, a atividade é considerada práxis a partir do pressuposto que "[...] é uma atividade que se desenvolve de acordo com finalidades, e essas só existem através do homem, como produto de sua consciência" (VÁZQUEZ, 1997, p. 188).

Dando continuidade à pesquisa, ainda, foi questionado aos docentes, qual a postura assumida frente à práxis pedagógica aplicada aos seus discentes: sete professores dizem ser motivador/estimulador, cinco se julgam questionador/investigador, dois assumem ser mediador/facilitador e nenhum docente marcou as opções reflexivo e exigente/rígido (aparece soma menor que 19, pois cinco professores assinalaram mais de uma resposta, sendo assim foram excluídos dessa questão). Diante dos dados obtidos, verifica-se que os docentes do ensino superior preocupam-se em atingir suas metas tornando sua práxis pedagógica mais prazerosa e eficaz para promover a aquisição de diversos conhecimentos.

Independente de sua postura, o professor deve se conscientizar que os alunos possuem diferentes níveis de conhecimento e ao mesmo tempo valorizar os aspectos que este traz consigo como bagagem de conhecimento. Por isso, uma das propostas é pensar o professor universi- 
tário como colaborador do crescimento do volume de informações e conhecimentos novos, necessitando de uma re-elaboração permanente dos saberes construídos e produzidos em sua prática pedagógica, tendo em vista que esse olhar crítico torna-se um elemento considerado importante na produção e qualidade do ensino na universidade (SANTOS, 2010). Para tanto, estes profissionais precisam fazer da sala de aula, além de um lugar de transmissão de conteúdos teóricos, um local de aquisição de valores, independente da postura assumida, para que as relações entre professor e aluno tornem-se um fator decisivo no processo pedagógico. E ainda dentro do processo ensino-aprendizagem, o professor não pode $\mathrm{e}$ nem deve negar ao aluno a possibilidade de desenvolver sua autonomia, para que o mesmo perceba-se como um indivíduo que está inserido num contexto social, onde convive com a interação de outros indivíduos. Assim sendo, Lima (2010) diz que ser professor então passa a ter um caráter dinâmico, reflexivo, transdisciplinar e que, requer do profissional da educação uma articulação dos saberes de forma significativa, primando por uma visão de totalidade e não fragmentação, quer em sua formação continuada, quer no desenvolvimento de seu exercício pedagógico, fomentando, ainda, nos alunos o desejo de querer sempre mais e que o conhecimento não é acabado.

Ao se pensar nesse processo pedagógico, tem que se considerar a relevância da prática exercida pelo docente na formação do futuro profissional, que é o discente, e ao serem interpelados sobre essa relevância os docentes dizem, em linhas gerais, que é imprescindível para o sucesso da construção do conhecimento do aluno, uma vez pretendem preparar/ formar profissionais criativos, ativos, críticos, reflexivos e aptos a solucionarem problemas da prática profissional. Além de estimular a busca do conhecimento técnico e cientifico, mas, não esquecem que no individuo precisa ser trabalhado os aspectos culturais e morais, pois assim, esse futuro profissional poderá auxiliar na melhoria da realidade social e moral da sociedade em que vive.

Diante das mais diversas posturas que o docente assume frente aos discentes, as metodologias adotadas pelos mesmos e ao confrontar as respostas dadas a questão acima, a maioria dos entrevistados diz que é de fundamental importância o professor se manter atualizado para dar ao aluno subsídios e condições de uma formação mais concreta e relevante, 
e não se pode esquecer que os docentes do ensino superior têm autonomia de ministrar seu conteúdo conforme lhe seja conveniente. Bolzan e Powaczuk (2009) relatam que tendo em vista que o professor é sujeito da formação do aluno, considera-se que o processo ensino-aprendizagem se dá a partir das suas potencialidades e das exigências da profissão, no qual a interação com alunos, colegas e a própria prática possuem papel fundamental.

Ao se discutir sobre as metodologias e sua relevância na formação do aluno, cabe ao professor do ensino superior, pensar/refletir sobre o contexto que o cerca e/ou em que está inserido, pois por muitas vezes essas inquietações são oportunas a reflexão de uma docência mais significativa. De acordo com o explicitado nas respostas sobre a relevância da prática exercida pelo docente, os professores mostram ter consciência de que sua práxis pedagógica é de suma importância na formação do futuro profissional, e ainda nessa discussão, é possível ver um conjunto de ideias das quais os professores tem em mente para que se possa ofertar e, tentar ao máximo, assegurar/garantir um ensino (teórico-prático) de cunho significativo ao seu aluno.

É inegável que se o ensino tiver por excelência, professores capacitados, metodologias adequadas e alunos interessados, os benefícios para com os alunos serão os mais diversos possíveis e quando questionados sobre os benefícios que ele vê sobre a sua prática pedagógica no processo de ensino aprendizagem, deparamo-nos com as seguintes respostas: contribuem para torná-los mais críticos diante dos problemas existentes, no seu dia a dia e fazendo ser mais éticos no mercado de trabalho; formar profissionais abertos e interessados no conhecimento cientifico, porém sem negligenciar a conduta prática, tendo bom senso ao aplicar cada um desses conhecimentos adquiridos; oportunizar condições ao futuro profissional para que ele possa tomar decisões, questionar e mudar quando achar necessário e preparar um profissional para a realidade do mercado de trabalho.

Os benefícios mencionados acima só poderão ter êxito se a tríade, já mencionada, professor, aluno e aprendizagem, comungarem do mesmo objetivo, que é dar condições plenas ao aluno de uma formação de nível superior. Nessas condições se encaixam os já mencionados projetos de ensino, pesquisa e extensão, juntamente com conteúdos apropriados 
e metodologias adequadas a cada situação problema que o acadêmico vivenciará dentro da universidade. Situações essas que desencadearão diversos questionamentos dos alunos para as soluções desses problemas aplicados pelo docente. Com isso, espera-se atingir ou pelo menos aguçar o aluno para que se torne um ser mais ético, reflexivo e crítico para a sua profissão, sinta-se mais engajado nas situações problemas que encontrará no dia a dia do mercado de trabalho. Desta forma, consolidar um aprendizado mais sólido em que o aluno tenha habilidades e competências para um bom exercício profissional fora dos muros da universidade, para tanto, ao aplicar sua práxis pedagógica o professor deve agregar a base da sua formação com a sua ação didática na elaboração de metodologias apropriadas, para que o aluno possa progredir no processo ensino-aprendizagem, e consequentemente o professor consiga de fato formar profissionais com as qualidades já mencionadas.

Para se adequar a essa realidade o docente deve tornar-se um sujeito em permanente construção, através da formação continuada (investindo no autoconhecimento) e das experiências cotidianas, construindo com competência uma relação agradável com o aluno e de acordo com Demo (1997), assim, na sua prática docente, não há nada mais inovador do que repensar a própria ação, compreendendo que inovar é um processo constante de reconstrução e, para tanto, é preciso repensar a sua prática, realizando um processo dialético transformador. Dessa maneira, o professor oportunizará aos alunos o desenvolvimento do raciocínio crítico, capacidade de refletir, de problematizar, de criar, colocando em prática os conhecimentos apreendidos durante o processo de ensino-aprendizagem, pois com suas vivências na formação e interação com o acadêmico, construirá essa tal almejada prática reflexiva para a experiência profissional.

Em linhas gerais, o docente deverá, por meio de sua práxis pedagógica, estimular o desenvolvimento do aluno e, que por meio do ensino-aprendizagem, transformará/construirá sua identidade pessoal e profissional, sendo a educação, nesse sentido, entendida como um processo de transição de um estado para outro. Sob este olhar, Lima (2010) afirma que as escolhas metodológicas de intervenção do professor não podem desprezar a constituição e construção da individualidade do aluno por meio de atividades, que são entendidas como um momento de construção, mediada por provocações da metodologia e dos materiais selecionados pelo 
professor. Dessa forma, o professor deve planejar a práxis pedagógica que melhor se aplicará ao desenvolvimento do aluno, considerando, que em determinado momento da vida acadêmica deverá promover a sua autonomia em relação às descobertas e em outro momento será necessário confrontar as diversas ideias e visões decorrentes da sua formação.

\section{CONSIDERAÇÕES FINAIS}

No decorrer do processo de construção dessa pesquisa, de caráter qualitativo, muitas reflexões foram transpassando o processo que teve como linha norteadora a procura de respostas sobre questões da realidade da docência no ensino superior.

Na totalidade, os professores que se inserem no campo universitário, por inúmeras razões e interesses, são de variados conhecimentos e áreas de atuação e mediante as revelações dos professores, nota-se que os mesmos têm consciência em relação a sua formação, mas, compreendem que diante do contexto em que se apresenta não se pode ficar a mercê das titulações que possuem, precisam procurar por atualizações que reformulem suas ações e práxis pedagógicas a fim de alcançar uma melhoria do processo de sua própria formação e consequentemente do processo ensino-aprendizagem.

Para que os tão desejados resultados sejam alcançados com sucesso, vale ressaltar que os sujeitos do processo devem comungar do mesmo ideal e dessa forma, impõem-se que o professor, cada vez mais, se torne um profissional capacitado a enfrentar inúmeros desafios desencadeados pela escolarização em todos os níveis de ensino. Os professores priorizam as aprendizagens significativas, embasadas em práticas liberais e éticas. Para tanto, cada professor buscará e usará um caminho para aplicação de ações metodológicas no processo de formação profissional. Sendo, assim, necessário ter ética e respeito por si próprio, pelos alunos e por todo o corpo docente presente na instituição de ensino.

A realização dessa pesquisa permitiu, ainda, aos docentes um olhar mais demarcado acerca do que se faz, sente e percebe na docência do ensino superior, propiciando momentos enriquecedores nas leituras estabelecidas.

É de grande valia que se reflita sobre novas práticas pedagógicas, 
buscando o comprometimento com a educação e instigando por novas metodologias e se possível, encontrar novos horizontes para melhoria do ensino como todo, pois, espera-se que essas melhorias tragam benefícios significativos a formação do aluno e, consequentemente o deixará apto frente às solicitações do mercado de trabalho que é tão competitivo. Nesse sentido, a universidade precisa ser concebida como local de formação social e profissional, onde o processo ensino-aprendizagem seja estruturado de maneira reflexiva e criativa, valorizando sua ação e entendendo sua importância no processo de emancipação do homem.

Contudo, as reflexões apresentadas nesse estudo mostram que sobre formação de nível superior, os professores buscam como ferramentas de trabalho diversas manobras, a fim de enriquecer e aprimorar o conhecimento dos alunos, objetivando formar profissionais capacitados a enfrentar o mercado de trabalho e as situações adversas que podem surgir na sua atuação profissional. Diante de todas as considerações apontadas sobre a temática da pesquisa, e a permanência em aberta do diálogo, sugere-se que profissionais da área, pesquisem mais sobre o tema, contribuindo, assim, para uma maior reflexão do assunto e um posterior estudo ainda perspectivando esta temática.

\section{REFERÊNCIAS}

ANDRÉ, M. E. D. de A.; OLIVEIRA, M. R. N. S. O. Alternativas no ensino da didática. 8. ed. Campinas, 1997.

ANDRÉ, M. P. et al. O papel da pesquisa na formação e na prática dos professores. Campinas: Papirus, 2001.

ARANTES, A. C. Competências básicas para ser um professor: ministrando aulas de educação física infantil em um curso profissionalizante. Colégio Brasileiro de ciências do esporte. Renovações, modismos e interesses. In: CONGRESSO BRASILEIRO DE CIÊNCIAS DO ESPORTE, 10., 1997, Goiânia. Anais... Goiânia, v. 1, p. 25-25, out. 1997.

BOLZAN, D. P. V.; POWACZUK, A. C. H. Docência universitária: a construção da professoralidade. Revista Brasileira de Formação de 
Professores, v.1, n. 3, dez. 2009. Disponível em: <http://itp.ifsp.edu.br/ ojs/index.php/RIFP/article/view/660/652>. Acesso em: 02 maio 2016.

BRASIL. Lei no 4.881-A, de 06 de dezembro de 1965. Dispõe sobre o Estatuto do Magistério Superior. Diário Oficial [da] República Federativa do Brasil, Brasília. Disponível em: $<$ http://www.planalto. gov.br/ccivil_03/leis/1950-1969/L4881A.htm>. Acesso em: 21 abr. 2016.

. Ministério da Educação. Lei no 9.394, de 20 de dezembro de 1996: Lei de diretrizes e bases da educação nacional. Disponível em: $<$ http://www.planalto.gov.br/ccivil_03/leis/L9394.htm>. Acesso em: 20 abr. 2016.

. Secretaria de Educação Média e Tecnológica.

Parâmetros curriculares nacionais: ensino médio. Brasília: $\mathrm{O}$ Ministério, 1999. Disponível em: <http://www.cpt.com.br/pcn/pcnparametros-curriculares-nacionais-do-ensino-medio>. Acesso em: 20 abr. 2016.

DEMO, P. Conhecimento moderno: sobre ética e intervenção do conhecimento. Petrópolis: Vozes, 1997.

GHILARDI, M. I. Mídia, poder, educação e leitura. In: BARZOTTO, V. H.; GHILARDI, M. I. (Orgs.). Mídia, educação e leitura. São Paulo: ALB e Anhembi Morumbi, 1999. p.103-112.

GIL, A. C. Como elaborar projetos de pesquisa. 4. ed. São Paulo: Atlas, 2002.

2008.

. Métodos e técnicas de pesquisa social. São Paulo: Atlas,

GÓMEZ, A. I. P. A cultura escolar na sociedade neoliberal. Porto Alegre: Artmed, 2001.

IMBERNÓN, F. Formação docente e profissional: formar-se para a mudança e a incerteza. São Paulo: Cortez, 2000. 
LIMA, M. B.; CORRÊA, M. B. A importância da formação continuada para professores do ensino Proeja. 2010. Disponível em: $<$ http:/www.senept.cefetmg.br/galerias/Anais_2010/Artigos/GT8/A_ IMPORTANCIA_DA_FORMACAO.pdf >. Acesso em: 24 fev. 2016.

LIMA, P. G. Formação de professores: por uma ressignificação do trabalho pedagógico na escola. Dourados: EDUFGD, 2010.

LÜDKE, M.; ANDRÉ, M. E. D. A Pesquisa em educação: abordagens qualitativas. São Paulo: EPU, 1986.

MARCONI, M. A.; LAKATOS, E. M. Fundamentos de metodologia cientifica. 5. ed. São Paulo: Atlas, 2003.

NAVES, A. T. Metodologia do ensino superior. Umuarama: Unipar, 2015.

NÓVOA, A. Os professores e a sua formação. Lisboa. Publicações Dom Quixote, 1992.

PERRENOUD, P. Construir competências é virar as costas aos saberes? Revista Pátio, Porto Alegre, a. 03, n. 11, p. 15-19, nov.1999. Disponível em: <https:/www.unige.ch/fapse/SSE/teachers/perrenoud/php_main/ php_1999/1999_39.html>. Acesso em: 17 maio 2016.

PIMENTA, S. G. Formação de professores: identidade e saberes da docência. In: . Saberes pedagógicos e atividade docente. 6 . ed. São Paulo: Cortez, 2008. p.15-34.

. Saberes pedagógicos e atividades docentes. São Paulo: Cortez, 2000.

. Trabalho e formação de professores: saberes e identidade. In: VALFREDO, S. F. (Org.). Educação: novos caminhos em um novo milênio. João Pessoa: Autor Associado, 2001.

PIMENTA, S. G.; ANASTASIOU, L. G. C. Docência no ensino superior. São Paulo: Cortez, 2002. 
SANTOS, M. S. G. Saberes da prática na docência do ensino superior: análise de sua produção nos cursos de licenciatura da UEMA. 2010. 193 f. Dissertação (Mestrado em Educação) Universidade Federal do Piauí, Teresina, 2010.

TARDIF, M. Saberes docentes e formação profissional. Petrópolis: Vozes, 2002.

VÁZQUEZ, A. S. Filosofia da práxis. Rio de Janeiro: Paz e Terra, 1997.

Recebido em: 05/09/2016 Aprovado em: 28/03/2017 